\title{
Weathering and its Potential Effect on Mine Slope Factor of Safety
}

\author{
Chakufola S $^{1}$, P R K Chileshe ${ }^{2}$, E B Samuel ${ }^{3}$ \\ ${ }^{1,2}$ Department of Mining Engineering, Copperbelt University, Zambia \\ ${ }^{3}$ Department of Mathematics, Copperbelt University, Zambia
}

\begin{abstract}
:
Introduction: Weathering is the transformation of lithological, chemical and physical character of a rock or soil in a mined slope, after excavation when it is exposed to atmospheric agents and derivatives. The changes caused degenerate the mechanical and physical strength of a rock or soil, which compromises the stability of mined and backfilled slopes during mine operations.

Problem: Some slopes at a Zambian Copperbelt open pit mine site, have been observed to experience various degrees of weathering which has contributed to a number of slope failures.

Objective: In this paper, the main objective was to evaluate the influence of weathering on the geotechnical properties of materials on pit slopes through the computation and evaluation of factors of safety for slope stability in weathered and un-weathered strata.

Method: Desk studies were conducted with detailed review of the available company, national and global literature concerning the effects of weathering on geotechnical properties as well as past reports on the weathering effects on slope stability at the study site. Mining and geotechnical personnel were also interviewed, followed by reconnaissance slope survey in various open pits at the mine to assess and verify the degree of weathering and related slope instability. This facilitated the building of a qualitative and quantitative geotechnical database which was used to provide or estimate input parameters for computation of factors of safety for slope stability for weathered and un-weathered strata. This was followed by computation of the factors of safety for open pit slopes alternating five different rock formations using moments analysis and AutoCAD Fellenius type construction for slope failure (to toe) and base failure (below toe) as well as, for comparison as an independent benchmark, a commercial computer software "SLIDE". Weathering in mined slopes for slope stability was simulated by downgrading measured input parameters, specifically, cohesion, friction angle and density.

Results and interpretation: At the mine site, weathering in mined slopes varied from imperceptible in strong siliceous/quartzitic rock to very pronounced in some areas, and sometimes even within the same slope, especially those of mixed lithology, without a proven timescale as to pre- or post-mining. Water was identified as the main source of weathering in the mine strata. Contribution to weathering in the mined slopes by effects due to air were also perceptible, to a lesser extent, although hypothesised to be significant in backfill slopes due to aeration during loading, transportation and dumping. Slope factors of safety were depressed by weathering. Conclusion: It was clearly observed and calculated that weathering action reduces the rock mass strengths in weathered mined and backfill slopes. This destabilises the slopes by reducing the factor of safety with time. However, though no specialised techniques were used, but with extensive observations and using theoretical analyses, actual design parameters, computer programs such as SLIDE, AUTOCAD to draw failure profiles and EXCEL spreadsheet calculations, it was concluded with reasonable confidence that: weathering affected rock mass strength through weakening of geotechnical properties of materials on mined slopes with water as a main weathering agent. The critical factor in weathered materials appeared to be cohesion.

Recommendations: To avoid aeration and water weathering of mined slopes, consideration should be given to coverage by geocomposite materials or impermeable soil like laterite. Cambering of the slope surface to provide water drainage away from slope edges is another option, which is already widely practiced by many Zambian open pits. Grout curtains to cut off strata water or river water from going into specific areas and strata of open pits have been successfully used in the past, for example, in Poland next to the Vistula River.
\end{abstract}

Keywords: factor of safety, Fellenius, mined slopes, slope failure, slough, weathering, Zambia.

\subsection{Problem Statement}

\section{Introduction}

Most ground movement problems in slopes in the open pits at the mine site under study and around the Copperbelt $[1 ; 2]$ are believed to be associated with the influence of weathering on mined pit slopes. The studied mine site was in the Copperbelt Province of Zambia, where numerous copper and cobalt ore open pits as well as dolomite quarries, for lime and cement production, have been mined in the past 60 years and continue to be

DOI: 10.9790/0990-0503012133 $\quad$ www.iosrjournals.org $21 \mid$ Page


mined. The area is subtropical savannah with heavy rainfall for six months annually, alternating with six months equally divided between a very hot season and a very cold, sometimes, frosty season. Slope problems with weathering are predominantly associated with water in and around mined slopes. However, the introduction of backfill in some open pits has added the extra dimension of weathering by a combination of aeration and water. Pit slope instability has proven to be problematic in open pit mines due to their exposure to weathering agents that alter the geotechnical properties. As a result of this problem, the studied mine has suffered a number of slope failure setbacks, which have caused disruption of copper ore production, mostly, but thrice resulted in loss of life, and property damage.

\subsection{Objectives}

The paper reports on the main objective which was to determine the influence of weathering on geotechnical properties of materials in mined slopes.

Subsidiary objectives were to:

- Review weathering and its influence on mined pit slopes.

- Compute factors of safety for weathered and un-weathered mined slopes in order to determine the influence of weathering on the stability of mined slopes.

- Recommend preventive and remedial measures that can be put in place to reduce the effects of weathering on mined pit slopes.

\section{Concept Of Weathering}

Weathering in soil or rock refers to the changes to these materials caused by weather and concomitants arising from the weather of a chemical, physical or biological nature. This produces the regolith, also termed a rock blanket, below the land surface. Mining takes place underground or from surface in the regolith as well as below in the solid rock. Soil is the topmost few metres of the regolith, and characteristically also contains organic matter, and is in itself a degradation of rock. When rock or soil is exposed by mining on the surface of the earth, the effects within the material are very pronounced compared to when very deeply buried. Gases, liquids and solids created by the weather interact with the physical, chemical and biological structure of the soil and rock. The rock and soil will throughout their geological history already have undergone various physical, chemical and biological processes to be formed, recognisably, as what they are now. Beyond that, due to continuous activity in the atmosphere and within the earth, some degree of alteration will have continued to occur up to the present day. Other assessments, of rock grade and slope instability, elsewhere, have shown that weathering is a predisposition factor in natural slope instability [3]. Of the greatest interest, in this paper, is the weathering which causes changes in mined or cut slopes which form part of open pits, open casts and other surface mining excavations. When rock and soil are under deep cover, access to them by atmospheric agents and their derivatives is limited or eliminated. When mining of the superincumbent or adjacent material takes place, the slopes of the remaining mining excavations are exposed to the atmospheric gases, liquids and solids generated by the weather. Chemical, physical and biological interactions in the mined slope with atmospheric agents accelerate beyond what was happening before mining. Interactions within the slope between slope materials and atmospheric agents may well have stabilised over the geological ages, but may renew and accelerate after slope mining. That is, the chemical, physical and biological characteristics of the rock and soil may start changing to various degrees, often deteriorating, rather than strengthening, the mechanical character of the rock and soil. To a lesser extent, it is possible that under some circumstances due to chemical reactions within the slope, the rock and soil may chemically and physically harden, rather like what happens with certain types of concrete over prolonged exposure to the atmospheric moisture. This is uncommon, to a larger extent most mined slopes deteriorate, to some degree, for example, clayey and shaley rocks and soils which kaolinise or swell. Even when deeply buried, air and water may gain access from the slope surface through fractures, joints, fissures and cracks to cause spheroidal weathering [4] or chemical exfoliation [5]. Physical and chemical weathering [5,6] are exemplified by Figure 1, while biological weathering [7] is best explained as due to intrusion and actions of plants, animals and micro-organisms in the mined or backfilled slopes. 


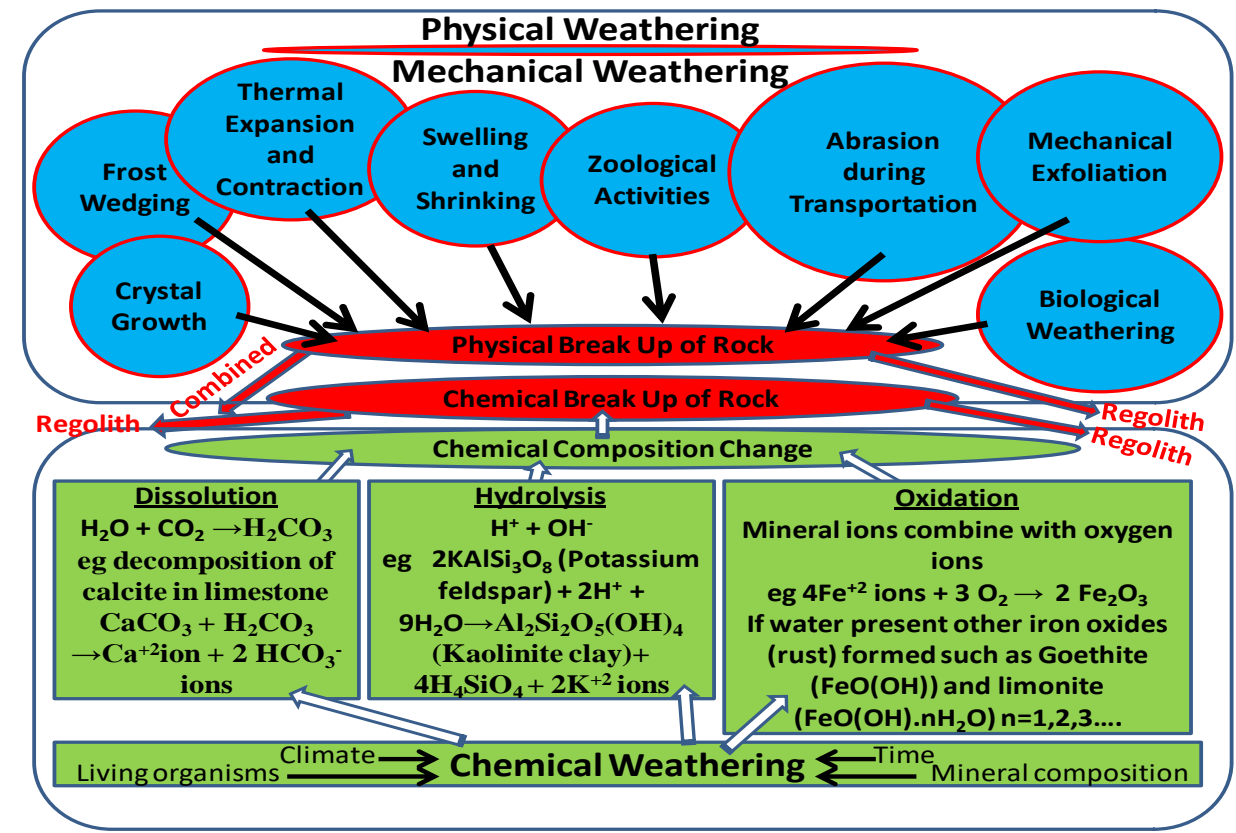

Fig 1: Physical and chemical weathering in geological materials which produces land regolith (soil and broken rock) in which some mining takes place

Mined slopes may deteriorate fairly rapidly in weeks or over many years, if not centuries, dependent on the severity and extremity of the weather, on the one hand, and a combination of many factors on the other. Such changes will affect the capacity of the slope that is, reducing the shear strength, density and cohesion of the slope material, thus, compromising its ability to stay intact in the way it was mined, resulting in planned or unplanned ground movements.

\subsection{Classification of Weathering}

The main agents of weathering in mined slopes are atmospheric air as well as seasonal and ground water and snow. Factors most affected by weathering are lithology, cohesion and frictional strength. Geological structure may be a factor in some situations especially folding and faulting, while dynamic forces may be ascribed to blasting and acts of God. To this list, may be added the density of the material which may change as a result of weathering and control the overall weight and loading of the slope. In this paper, model input parameters in terms of cohesion, angle of internal friction and density were varied to imitate weathering. Grades of weathering $[8,9]$ which, here, were simply noted during the study but not directly used, can be employed empirically to estimate cohesion and angle of internal friction.

\section{Concepts Of Slope Failure Mechanisms And Weathering}

The fact that slopes are weathered is not only significant for mining purposes but for other sectors of society as well due to the propensity of such slopes to slough, especially in very wet or snowy winter months, or afterwards, creating hazardous conditions for people, infrastructure, property and equipment.

Some of the driving factors in ground movement in weathering slopes [10] are:

- Slope geometry;

- Geological structure;

- Lithology;

- Seasonal and groundwater and snow;

- Dynamic forces;

- Cohesion; and

- $\quad$ Frictional strength (angle of internal friction).

In mined slopes, geological structurally-related predominant failure modes [11] include:

- Planar failure;

- Wedge failure; and

- Toppling failure.

Where geological structures are not the only issue, especially in weak and or heavily jointed rockmasses, other failure modes may occur such as:

- Rotational failure (circular), which includes slope (to toe) and base (below toe) failures; and 
- Mass flow.

The two types of slope failure enumerated above are very common at the study mine site, and the scope of the present study was targetted at slope and base failures as listed above, and discussed later.

\section{Slope Management At Study Site}

To enhance the safety of people, infrastructure, property and equipment, mined slopes have to be carefully monitored in order to facilitate mitigation or prevention of slope failure during and after the life of mine. Typically monitoring is done in several ways at the mine site:

- Regular visual inspections of early signs of instability, such as loose rocks and cracks;

- Monitoring tension crack dilation;

- Prism displacement monitoring employing the EDM and GPS units;

- Continuous surface displacement monitoring using wire line extensometers linked to automatic warning devices in the event of excessive slope movement;

- Slope monitoring involves the use of survey pegs on a regular basis in order to detect any slope movement in areas susceptible to slope movement; and

- A computerised slope monitoring and management is also carried out using the Slope Stability Radar (SSR) [12]. Mining is not allowed without this radar cover in geotechnically sensitive areas [13].

\section{Methodology}

Data collected for this project work included both primary and secondary using a number of different approaches as below.

\subsection{Secondary data collection}

Secondary data was gathered primarily through desk study and interviews.

Literature review

In this approach, a detailed review on the available literature such as company production and technical reports as well as literature from the internet concerning the effects of weathering on geotechnical properties was conducted. This included reviewing past reports on the effects on slope stability at the open pits on the mine.

Interviews

As a part of establishing the impact of weathering on slope stability at the mine, interviews were carried out with mainly mining geotechnical engineers from the open pit and also the maintenance. Questions such as the following were asked.

- What are the areas affected by weathering action in the pit?

- What was the history and nature of weathering related slope failures at the mine?

- How are the pits designed relative to weathering on the surface?

- What the resulting effects of weathering on surface are as manifested during mining operations?

- What is the effect of weathering action on surface strata geotechnically?

\subsection{Reconnaissance survey}

During reconnaissance survey, the open pits affected by weathering were visited. The main aim of these, were to verify the data collected about the weathering effects on surface and slope stability.

\subsection{Detailed site investigation}

In this approach a comparison was made between the data collected at desk study and that obtained during the physical observation of weathering action on the surface and open pit slopes. The influence of weathering on the exposed rock strata forming slopes faces was investigated by comparing the factors of safety for weathered and un-weathered strata zone in the pit. This was done by calculating the factor of safety for weathered and un-weathered scenarios for stacks of five different rock formation using slope failure analysis, base failure analysis and a computer software "SLIDE", the latter as an independent benchmark.

\section{Qualitative And Quantitative Data Collected And Findings}

Qualitative and quantitative data was collected from study of weathering at the mine site, review of case studies of slope failures and failure mechanisms at the mine site, evaluation of geotechnical conditions and model input parameters as well as open pit design parameters, as discussed below.

\subsection{Weathering at Studied Mine Site}

The mine site used for this study is in the Zambian Copperbelt at around $1300 \mathrm{~m}$ above mean sea level where the climate is subtropical savanna, with climate being a six month rain season (800 to $1300 \mathrm{~mm}$ for the period) from November to April the following year. The dry season from May to October is characterised by, 
first, a very cold three months, with rare frost, and then a hot dry three months weather. Clearly this type of weather provides ample seasonal rainwater seepage into the ground at the mine and the surrounding. The significance of the impact of water at the mine has been studied over time since mining started [1]. Coupled with the great variations in temperature from just above freezing in the winter $\left(7^{0} \mathrm{C}\right)$ in the night to just above $35^{\circ} \mathrm{C}$ during hot days, significant changes in temperature, water and air in slopes is normal in mined slopes. Under such conditions, weathering is to be expected, and has been noted from observations of component materials in weathered slopes, varying from weathering grade I (mostly) to VII (for some slopes), dependent on the location, length of exposure and lithology [3,4]. At the mine site, weathering in mined slopes varied from imperceptible in strong siliceous/quartzitic rock to very pronounced in some areas, and sometimes, even within the same slope, especially those of mixed lithology, without a proven timescale as to pre- or post-mining. Water was identified as the main source of weathering in the mine strata. Contribution to weathering in the mined slopes by effects due to air was also perceptible, to a lesser extent.

Another aspect of weathering at the mine has been to do with backfilled slopes, where the material was mined somewhere in the pit and then transported several kilometres to another area as backfill. Some of the backfill was rehandled more than once.. Such backfilled slopes have experienced extreme aeration from the atmosphere during the process of mining, transportation and dumping. In addition to this, the backfilled slopes in the pit have then experienced water percolation from strata and seasonal rainfall. Due to the greater stacking heights, such slopes have been a matter of safety and production concern at various times. These backfilled slopes while important were not the subject of this study.

\subsection{Case studies of slope failures and failure mechanisms at the studied mine site}

From company production and safety reports, it was established that the mine has a long history of ground movement in mined and backfilled slopes. The slope failures at the mine are mostly in form of "slope sloughing". The ground movement, called "sloughs" at the mine, has been minor, but sufficient to affect production in some way, or major, to the point of total disruption of a pushback or a dump, with threatened or actual property damage. Exceptionally, in terms of fatalities, one slough caused ten fatalities in 2001 and there was a rockfall in 1984 which killed one. Most ground movement in slopes, outside of mine slope design issues, have been to do with water in the slope, with the origin of water being either the strata itself or seasonal rainfall seepage. In such scenarios the main factor in weathering in the slope has been water. Here, cases of pore water pressure build up in the slope are distinguished from weathering effects where constituent material properties have been degraded physically and or chemically.

\subsection{Geotechnical conditions and model input parameters}

Geotechnically, weathering action in the mined slope can reduce the rock properties. The geotechnical parameters for the studied mine's rock strength parameters (density, cohesion and friction angle) in weathered and un-weathered strata zones are shown in Table 1 . The un-weathered data were provided by the mine. This data basically reflected the observation at the mine that weathered materials essentially lost their cohesion, $\mathrm{C}$ in equation 3 leading to the significant depression of the shear strength, $S$, in equations 2 , causing the resisting moments, the numerator, in the factor of safety equation 1 to depress. Reductions in angle of internal friction and density were relatively comparatively marginal, less than $22 \%$ mostly. Although the density figures were notably lower than the global [14], they were accepted as given.

TABLE 1: Mine rock properties (weathered and un-weathered)

\begin{tabular}{|c|c|c|c|c|c|c|c|c|c|}
\hline \multirow[b]{2}{*}{ Rock Formation } & \multicolumn{3}{|c|}{ Mean Cohesion C (kPa) } & \multicolumn{3}{|c|}{ Mean Friction Angle $\Phi\left({ }^{0}\right)$} & \multicolumn{3}{|c|}{ Mean Dry Density $\left(\mathrm{kg} / \mathrm{m}^{3}\right)$} \\
\hline & $\begin{array}{c}\text { Unweathered } \\
\text { Measured }\end{array}$ & \begin{tabular}{|c|} 
Weathered \\
Assumed
\end{tabular} & $\begin{array}{l}\text { Weathered as } \\
\quad \% \text { of } \\
\text { Unweathered }\end{array}$ & $\begin{array}{c}\text { Unweathered } \\
\text { Measured }\end{array}$ & $\begin{array}{l}\text { Weathered } \\
\text { Assumed }\end{array}$ & $\begin{array}{c}\text { Weathered as } \\
\% \text { of } \\
\text { Unweathered }\end{array}$ & $\begin{array}{l}\text { Unweathered } \\
\text { Measured }\end{array}$ & $\begin{array}{l}\text { Weathered } \\
\text { Assumed }\end{array}$ & $\begin{array}{l}\text { Weathered as } \\
\text { \% of } \\
\text { Unweathered }\end{array}$ \\
\hline Dolomite type 1 & 44.05 & 8.18 & 18.57 & 24.83 & 23.03 & 92.75 & 1535.58 & 1466.04 & 95.47 \\
\hline Shale type 1 & 158.14 & 11.80 & 7.46 & 28.71 & 25.40 & 88.47 & 1645.97 & 1410.30 & 85.68 \\
\hline Dolomite type 2 & 53.64 & 4.69 & 8.74 & 25.92 & 20.46 & 78.94 & 1578.37 & 1417.17 & 89.79 \\
\hline Dolomitic Schist type 1 & 99.85 & 12.15 & 12.17 & 21.69 & 19.52 & 90.00 & 1752.23 & 1439.31 & 82.14 \\
\hline Quartzite type 1 & 172.25 & 15.69 & 9.11 & 35.13 & 29.57 & 84.17 & 1673.76 & 1562.90 & 93.38 \\
\hline
\end{tabular}

\subsection{Open pit design parameters}

To ensure the safety of the open pit and dump slopes, and to attain the minimum required factor of safety for temporary slopes of 1.1 or 1.2 factor of safety threshold for permanent benches at the mine, very elaborate geometrical design parameters and slope guidelines have been developed from precedent and 
theoretical analyses, and are used to design and lay out the bench slopes, as a standard, and were utilised for this study, but are not shown here.

Data collected was analysed by:

\section{Data Analyses}

- Basic slope stability analysis using moments applied to, on one hand, un-weathered five strata in a slope and, on the other hand, to the same material whose geotechnical characteristics had been deliberately altered to imitate weathering under the following conditions;

- Base failure; and

- Slope failure.

- Slope failure analysis using SLIDE slope stability commercial software. The choice of software was dictated by the ready availability of the software at the site, being used by the mine as their standard.

\subsection{Basic slope stability analysis using moments}

In any assessment of the effects of weathering on the slope stability, one must consider the actual signs of instability in the pit walls and the degree to which they are attributable to weathering. Recorded instability within the open pit mine can be classified in terms of:

- The inherent factor of safety of the slope before failure.

- The amount of weathering at the time of failure

In this way the response of the slope to weathering can be qualified and quantified. However, the two factors that must be considered in evaluating the impact of weathering on slope stability include:

- Position of the tension zones created by weathering which could cause tensile cracks in the open pit face as this is a sign of a pending slough; and

- The level of weathering of the slope which could reduce the overall rock mass shear strength (values of cohesion, internal friction and density) in response to the differential movements associated with weathering.

Two failure mechanisms considering the weak nature of rock mass surrounding the slope face at the studied mine were assumed, these included:

- Base rotational failure.

- Slope rotational failure.

It should be noted that apart from using the recommended mine design parameters, the projected failure surfaces for both base and slope rotational failures were drawn using AUTOCAD, similar to Fellenius [15]. The geometrical parameters such as the area of sliding rock mass (block) and the length of the slip plane were obtained from these models as generated by the AUTOCAD program.

The stability analyses factor of safety calculations were as shown in sections 7.2.1 and 7.2.2, based on geometrical parameters derived from the AUTOCAD models, mine design parameters and EXCEL spread sheets. The factors of safety $[16 ; 17]$ were computed for different rock formations considered in both weathered and un-weathered strata zones.

Slip circle technique factor for safety is given by the following formulae below [16;17; 18]:

FACTOR OF SAFETY $=\frac{\text { Resisting moments }}{\text { Driving moments }}$

Resisting moments $=\mathrm{W}_{2} \mathbf{1}_{2}+\mathrm{SLR}$

$: \mathrm{S}=\mathrm{C}+\mathrm{Wh} \tan \phi$

$\mathrm{h}=\frac{\mathrm{H}}{2}$

$\mathbf{W}=\mathbf{A} \gamma_{\mathbf{r}}$

Driving moments $=\mathrm{W}_{1} \mathbf{1}_{1}$

Where:

$\mathrm{S}=$ shear forceon the slip plane $\left(\mathrm{kN} / \mathrm{m}^{2}\right)$

$\mathrm{L}=$ length of the slip arc (metres)

$\mathrm{R}=$ radius of the slip arc (metres)

$\mathrm{H}=$ bench height (metres) 
$\mathrm{C}=$ cohesionof the rock $(\mathrm{kN})$

$\phi=$ internal friction angle for the rock material $\left({ }^{\circ}\right)$

$\gamma_{\mathrm{r}}=$ unit weight of $\operatorname{rock}\left(\mathrm{kN} / \mathrm{m}^{3}\right)$

$\mathrm{A}=$ area of the block $\left(\mathrm{m}^{2}\right)$

$\mathrm{W}=$ weight of the block $(\mathrm{kg})$

$\mathrm{W}_{1} \mathrm{l}_{1}=$ driving moment of weight of sliding block about the centroid $(\mathrm{kN})$

$\mathrm{W}_{2} \mathrm{l}_{2}=$ resis tingmoment of weight of s maller block about the centroid $(\mathrm{kN})$

\subsection{Application of moments slope stability analysis to weathered and un-weathered strata}

The analysis used to determine the influence of weathering of geotechnical properties of materials on the open pit slopes was based on simulation of the weathering. The effects of weathering was assessed on a comparative basis by computing the factors of safety for the hanging wall slope using un-weathered strata strength values and re-computing with the same slope configuration using the weathered strata strength values. A sample spreadsheet calculation is shown in Table 2.

TABLE 2: Spreadsheet sample calculation of factor of safety for base failure of un-weathered dolomite type 1

\begin{tabular}{|c|c|c|c|c|c|c|}
\hline PARAMETERS & INPUT & UNITS & \multirow{3}{*}{\multicolumn{4}{|c|}{ CALCULATIONS FOR THE GIVEN PARAMETERS }} \\
\hline Specific gravity, sg & 1.54 & & & & & \\
\hline Radius of the arc, $\mathrm{R}$ & 25.16 & $\mathrm{~m}$ & & & & \\
\hline Angle of friction, $\Phi$ & 24.83 & degrees $\left({ }^{\circ}\right)$ & SOLVED PARAMETER & VALUE & UNITS & \\
\hline Cohesion, c & 44.05 & $\mathrm{kPa}$ & Shear strength & 97.34 & $\mathrm{kN} / \mathrm{m}$ & \\
\hline Length of the arc, $\mathrm{L}$ & 44.71 & $\mathrm{~m}$ & $\mathrm{~W}_{1}$ & 3388.10 & $\mathrm{kN}$ & \\
\hline Cross sectional area under weight, $W_{1 ;} \mathrm{A}_{1}$ & 220.64 & $\mathrm{~m}^{2}$ & $\mathrm{~W}_{2}$ & 242.47 & $\mathrm{kN}$ & \\
\hline Cross sectional area under weight, $\mathrm{W}_{2 ;} \mathrm{A}_{2}$ & 15.79 & $\mathrm{~m}^{2}$ & Resisting moments & 110874.33 & $\mathrm{kNm}$ & \\
\hline Slope height; H & 15.00 & $\mathrm{~m}$ & Driving moments & 68575.22 & $\mathrm{kNm}$ & \\
\hline $\begin{array}{l}\text { Length from centroid to the centre line of } \\
\text { the circle under area } 1 ; l_{1}\end{array}$ & 20.24 & $\mathrm{~m}$ & Factor of safety, FOS & 1.6168 & & \\
\hline $\begin{array}{l}\text { Length from centroid to the centre line of } \\
\text { the circle under area } 2 ; l_{2}\end{array}$ & 5.77 & m & & & & \\
\hline Unit weight of water; $\gamma_{w}$ & 10.00 & $\mathrm{kN} / \mathrm{m}^{3}$ & & & & \\
\hline Unit weight of the material $; \gamma$ & 15.36 & $\mathrm{kN} / \mathrm{m}^{3}$ & & & & \\
\hline \begin{tabular}{|l|} 
Unit width \\
\end{tabular} & 1.00 & $\mathrm{~m}$ & & & & \\
\hline
\end{tabular}

7.2.1 Base failure

For the failure analysis, the factor of safety is found using equation (7). The base failure model in Figure 2 was done using Auto CAD and incorporating the mine's slope design parameters.

$\mathrm{FOS}=\frac{\left(\mathrm{W}_{2} \mathrm{l}_{2}+\mathrm{SLR}\right)}{\mathrm{W}_{1} \mathrm{l}_{1}}$ 


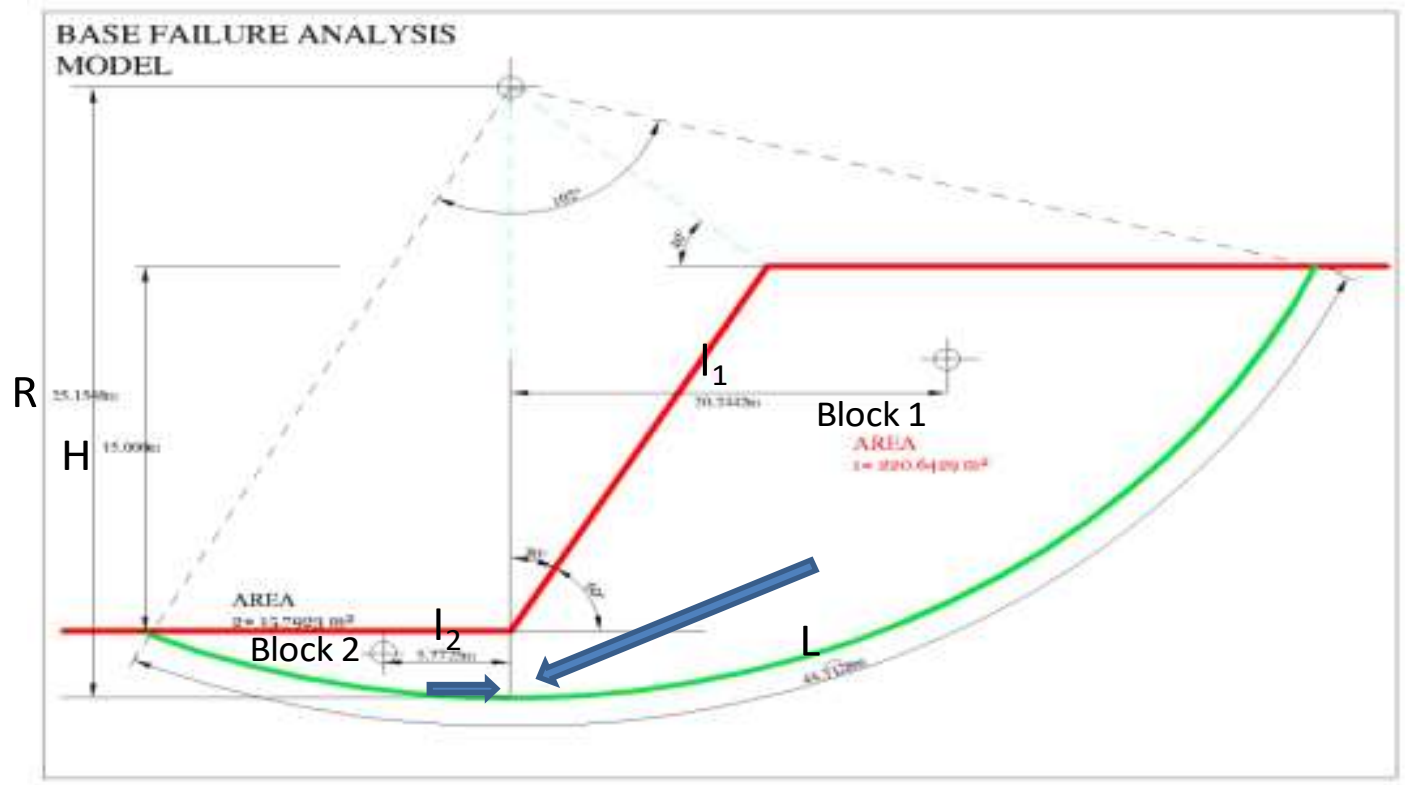

Fig.2: Base failure analysis model for individual rock formation

\subsubsection{Slope failure}

Factor of safety for slope failure was calculated using equation (8). Slope toe failure models in Figure 3 were done using AutoCAD and incorporating the mine's slope design parameters.

$$
\mathrm{FOS}=\frac{\mathrm{SLR}}{\mathrm{W}_{1} \mathrm{l}_{1}}
$$

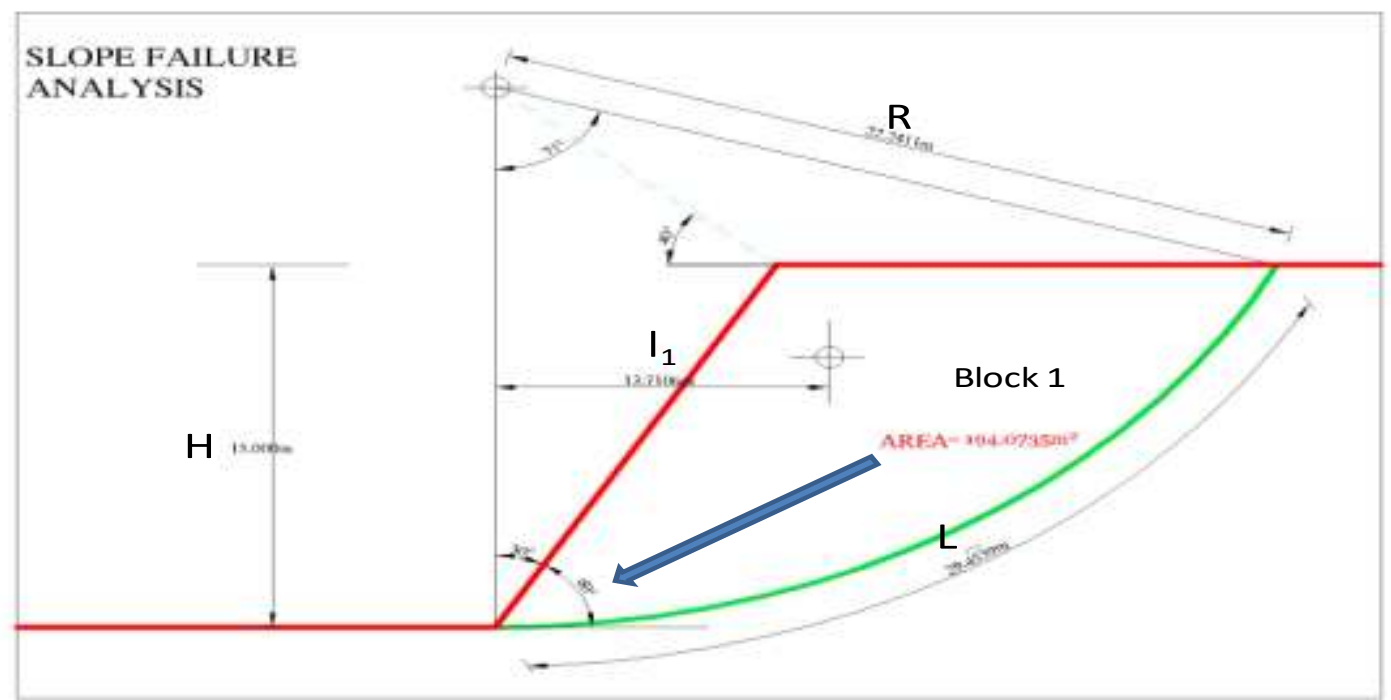

Fig. 3: Slope failure analysis model for individual rock formation

\subsection{Slope failure analysis using SLIDE software}

Slope failure analyses were also done using SLIDE commercial software (Figs. 4 and 5), as an independent benchmark. The input parameters for different rock formation (weathered and un-weathered strata zones) were analysed maintaining the same slope configuration. The following sample results were obtained from the analyses (Figs. 4 and 5). 


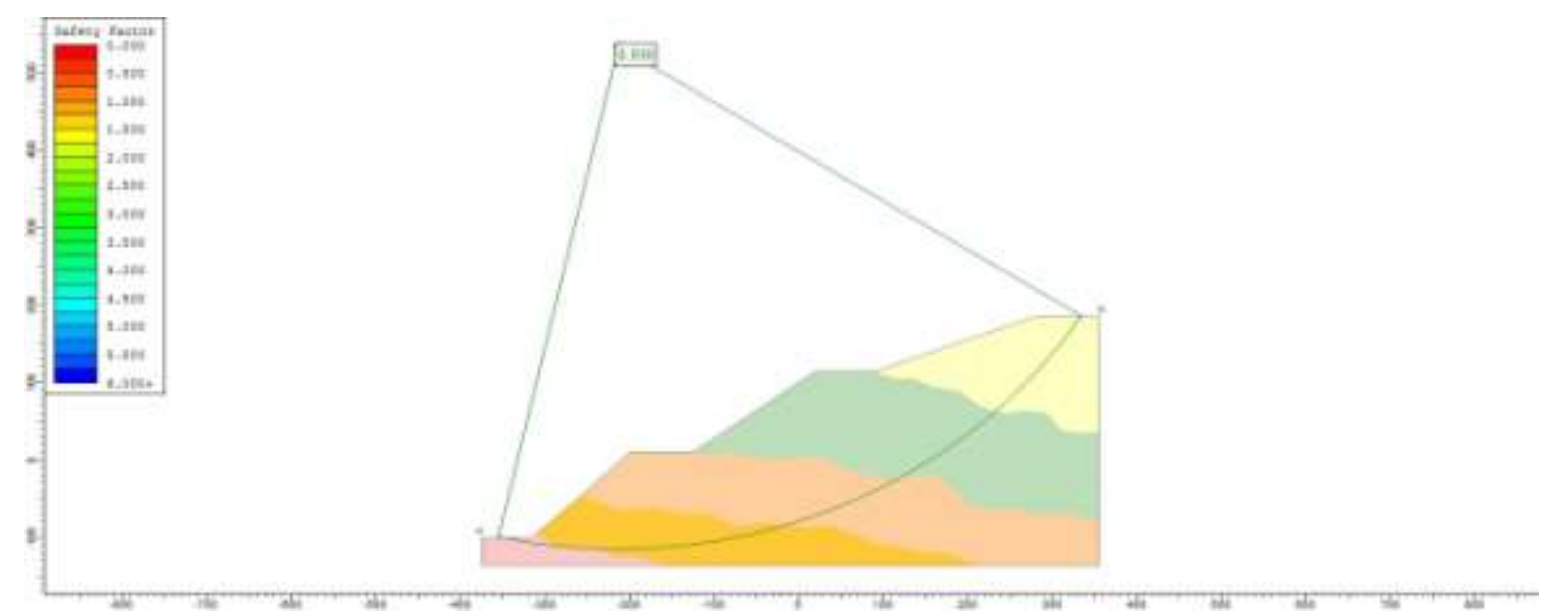

Fig. 4: An example of slope failure analysis model for a weathered stack from SLIDE

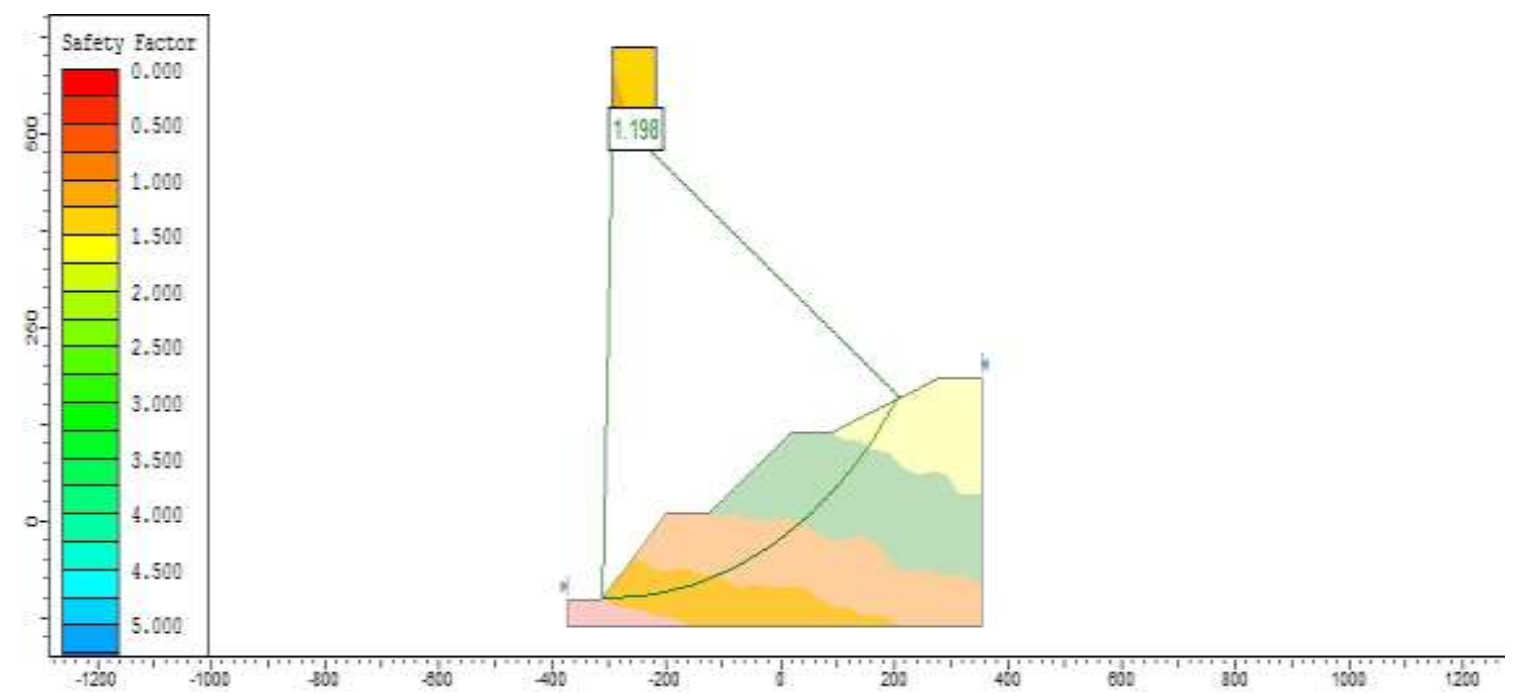

Fig. 5: An example of slope failure analysis model for an un-weathered stack from SLIDE

\section{Results And Discussions}

Results for weathering effects as well as slope failure analysis, base failure analysis and SLIDE software are analysed and discussed below. An effort at correlation of factors of safety data is also made, together with an overall assessment of the slope stability for un-weathered and weathered strata.

\subsection{Weathering effects}

Results, in Table 3, showed that slope failures occur as a result of weathering action on pit slopes. The weathering which affects the slope mostly influences stability by altering the geotechnical properties. This includes cohesion, density, friction angle and the particle arrangement of the material. It can be inferred that weathering is responsible for some degree of instability of cut slopes. Therefore two sets of data were used in the analyses, one to represent un-weathered, and the other to represent weathered materials, that is with altered parameters. Three analytical methods were used, the slope failure analysis, base failure analysis and SLIDE, to calculate the factor of safety in both conditions.

\subsection{Data analysis results and discussion}

The slope factor of safety and correlation results are summarised in Table 3. The factors of safety are also shown graphically in Figure 6.

In principle, as stated in section 6.3, while weathered material significantly lost cohesion, $\mathrm{C}$ in equation 3 , as reflected in the depressed input parameters for weathered assumed, the result was to reduce $\mathrm{S}$ in equation 2. This in turn reduces the numerator (resisting moments) in equation 1, and thereby the factor of safety, equation 1 , due to the denominator in equation 1 being only marginally depressed by the lowered density of the weathered material. The subsections below generally reflect this. 
TABLE 3: Factors of safety for un-weathered strata and weathered strata

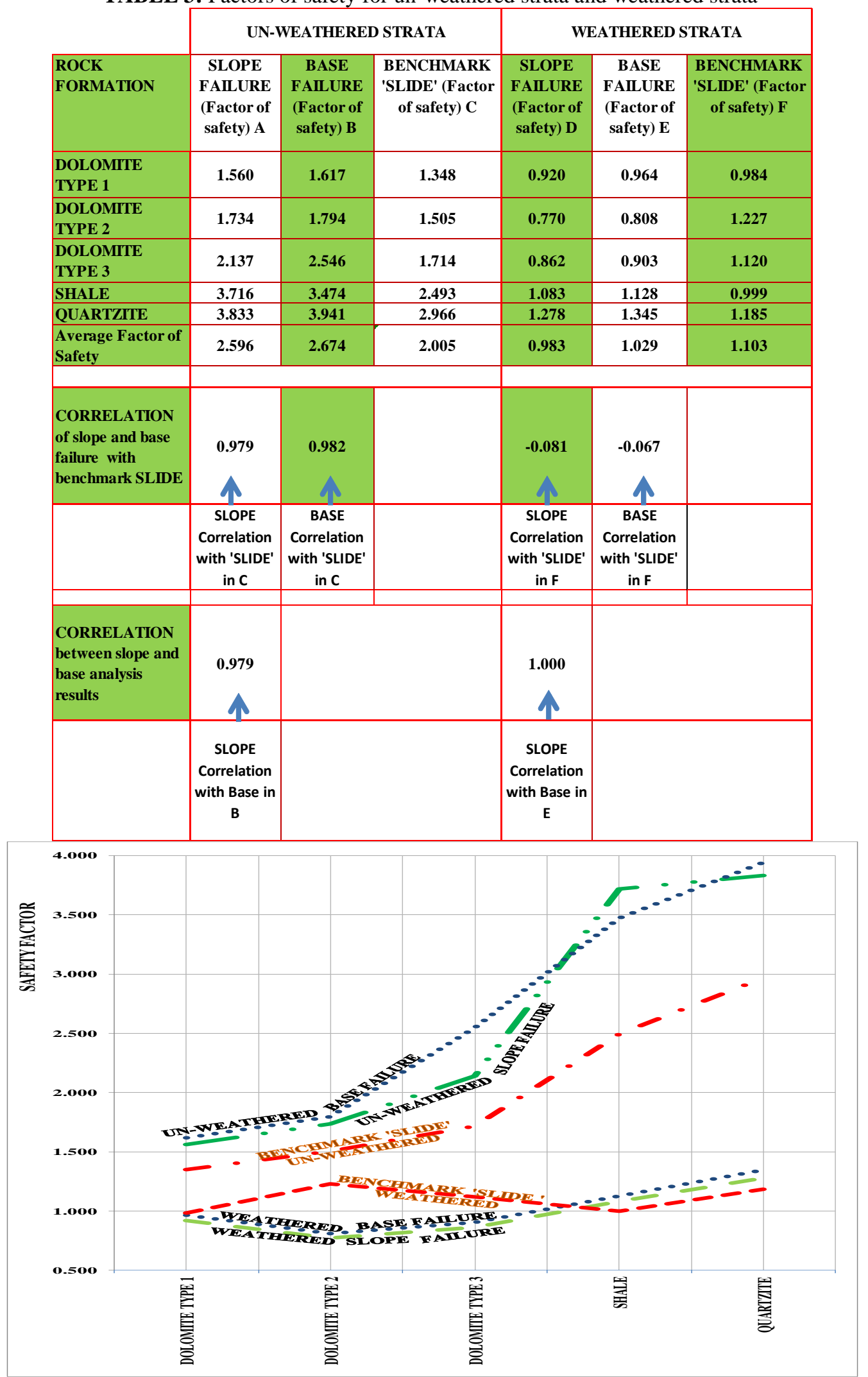

Fig.6: Factors of safety for un-weathered strata and weathered strata in graphical format

\subsubsection{Slope failure analysis results}

The first results obtained using slope failure analysis for the first case using un-weathered recommended parameters produced a mean factor of safety 2.596 . This factor of safety is very stable for all the five different 
strata zones. The second results obtained using slope failure analysis for the weathered data using altered parameters produced mean factor of safety 0.983.This factor of safety is considered unstable for the dolomites types 1, 2 and 3, while marginal factor of safety was obtained for shale (1.128) and minimum stability for quartzite (1.345). So, four of the five different weathered strata zones (Table 3; Figure 6) became either unsafe or marginally safe. In summary, the factors of safety for weathered material comparative to un-weathered material generally more than halved to unsafe or marginal safety, except for very strong durable rock such as quartzite, the critical factor appearing to be loss of cohesion, C.

\subsubsection{Base failure analysis results}

Results for base failure were similar to those for slope failure above. The first results obtained using base failure analysis for the first case using recommended parameters produced a mean factor of safety 2.674 . This factor of safety of safety is very stable for all the five different strata zones. The second results obtained using base failure analysis for the weathered data using altered parameters produced mean factor of safety 1.029. This factor of safety is considered unstable for the dolomites types 1,2 and 3 , while marginal factor of safety was obtained for shale and minimum stability for quartzite. So four of the five different weathered strata zones (Table 3; Figure 6) became either unsafe or marginally safe, except quartzite, which is generally exceptionally strong. In summary, un-weathered strata produced significantly higher factors of safety than weathered strata.

\subsubsection{Failure analysis results using SLIDE}

The first results obtained using SLIDE failure analysis for the first case using recommended parameters produced a mean factor of safety 2.005 . This factor of safety of safety is stable for all the five different strata zones. The results obtained using SLIDE failure analysis for the second case using altered parameters produced mean factor of safety 1.103.This factor of safety is marginally stable for three out of the five different strata zones (Table 3; Figure 6), with two completely unstable. In summary, un-weathered strata produced significantly higher factors of safety than weathered strata, confirming the results from the direct EXCEL calculations.

\subsubsection{Correlation of slope and base failure results with SLIDE}

From Table 3 and Figure 6, slope and base factors of safety correlated very strongly (positive) with each other for both weathered and un-weathered. SLIDE software was introduced to provide an independent benchmark for the analyses for slope toe and slope base failure analyses. SLIDE results correlated very positively with both slope and base failure results for un-weathered strata. SLIDE correlation with slope and base failure results for weathered was non-existent, reflecting perhaps, firstly, that the input parameters for weathered had been mere assumptions. Secondly, it could be speculated, since it could not be verified, that the SLIDE software, which had been picked for convenience, being readily available at the mine, possibly employed a dissimilar algorithm, to what was used to calculate factors of safety by this study, and was not suitable for highly weathered weakened strata.

\subsection{Slope failure field observations}

From the slope failures observed on the benches of the main mine, it can be stated that, qualitatively, slope failures experienced in these areas are significantly influenced by weathering effects on the geotechnical material properties on the pit slopes. Mathematically, as discussed above, the critical factor in weathering is the cohesion, with depression of other factors such as angle of internal friction and density being of relatively lesser impact.

\subsection{Slope stability summary}

The stability analysis conducted on the comparative basis based on the relative values of the factors of safety in two strata zones assumed, that is, weathered and un-weathered strata zones have indicated the significant reduction in the weathered strata zone compared to the un-weathered strata zone under the similar slope design parameters and failure mechanisms (Table 3; Figure 6). This reduction in the average factor of safety in weathered strata zone comparative to the un-weathered zone is due to the reduction in the overall rock mass shear strength values in this zone caused by both physical and chemical weathering. Therefore, under the similar slope design parameters, the slope in the weathered strata zone has the higher chances of failure due to increased level of instability caused by the reduction in the factor of safety as compared to the ones in the unweathered strata zone. The main factor seems to be cohesion. 


\subsection{Main objective}

\section{Conclusions}

The main objective was to determine the influence of weathering on geotechnical properties of materials on pit slopes. The results obtained from the data analyses clearly indicate that the factor of safety in the weathered materials reduces comparative to un-weathered, by half or more and, hence, increases slope instability. The greatest influence appears to be from loss of cohesion during weathering. The other factors such as density may also reduce but not to the same degree as cohesion.

\subsection{Specific objectives}

- The first specific objective was to review weathering and its influence on mined and backfilled pit slopes. Physical, chemical and biological weathering causes mined and backfilled slopes to deteriorate in terms of geotechnical properties, and thus cause reduced slope stability. Exceptionally, theoretically, some chemical weathering effects may cause hardening of materials, similar to that caused in cementitious materials by long term rain-water.

- The second specific objective was to compute factors of safety for weathered and un-weathered mined slopes in order to determine the influence of weathering on the stability of mined slopes. From slope failure, base failure and SLIDE analyses of the five contiguous strata at the study mine site, un-weathered strata produced significantly higher mean factor of safety than weathered strata:

- For slope toe failure, the factors of safety for weathered material comparative to un-weathered material generally more than halved to unsafe or marginal safety, except for very strong durable rock such as quartzite, the critical factor appearing to be loss of cohesion.

- For slope base failure analysis, weathered strata produced significantly lesser factors of safety than weathered strata, and as for slope toe failure, the critical factor being the loss of cohesion.

- From the analysis using a commercial software package, SLIDE, as a control benchmark for the five unweathered strata a mean value for factor of safety of 2.005 (very stable) was obtained, which reduced to 1.103 for weathered strata, barely stable even for short term slopes. Overall, independent the benchmark results confirmed the direct EXCEL calculations.

- There was almost perfect positive correlation between the commercial software SLIDE and the results for un-weathered strata slope toe and slope base failure. There was no correlation between SLIDE and the results for weathered strata, which were obtained through arbitrary assumptions.

\section{Recommendations}

The third specific objective was to recommend preventive and remedial measures that can be put in place to reduce the effects of weathering on mined or backfilled pit slopes.

- Geotechnical designs especially slope geometries must be re-evaluated for slopes that lie within the weathered zone so as to take into account the level of weathering that has been done to the rock mass surrounding the slope face. Cohesion needs special attention.

- Pit slopes excavated in areas that may be influenced by weathering, should be covered by either natural materials or geo-fabric.

- Drainage in the vicinity of slopes and cambering of the surfaces of slopes should be used to lead rain water away and to avoid impoundment, and resultant sub-surfaceseepage.

- Grout curtains to cut off strata water or river water from going into specific areas of open pits have been successfully used, for example, in Poland next to the Vistula River and can also be considered.

- It may be worth doing this exercise on weathered materials of a statistically significant sample of discrete variables (different strata). Ideally, taking un-weathered samples and testing them and then obtaining a sample from the un-weathered and weathering it would be the way to go, if practicable.

\section{Acknowledgements}

Authors extend their thanks to Copperbelt University and the Copperbelt of Zambia mining industry and fraternity for all manner of facilitation, too numerous to itemise individually.

\section{References}

[1]. Silwamba, C. and Chileshe, P.R.K. 2015a. Open pit water control safety: A Case of Nchanga Open Pit Mine, Zambia. International Journal of Scientific and Technology Research Volume 4, Issue 08, August 2015, pp 105. ISSN 2277-8616. www.ijstr.org

Silwamba, C. and Chileshe, P.R.K. 2015b. Risk evaluation and mitigation measures for slope management at Chingola Open Pit D\&F, Zambia. Southern African Institute of Mining and Metallurgy. Proceedings of Copper - Cobalt Africa 2015 in association with the 8th Southern Africa Base Metals Conference, Livingstone - Zambia, pp 26-31. www.saimm.co.za

[3]. Borelli, L., Greco, R. and Gulla, G. 2007. Weathering grade of rock masses as a predisposing factor to slope instabilities: Reconnaissance and control procedures. Geomorphology 87 pp 157 - 175. Published by Elsevier ScienceDirect. www.elsevier.com/locate/geomorph. $\quad$ PDF copy obtained 
from:http://www.cnr.it/istituti/Allegato_30014.pdf?LO=01000000d9c8b7a6090000000900000071360000ca709b530000000001000 $00000000000000000000000000000000000000000000000000000000000000000000000000000000000 \&$ type $=$ application $/$ pdf

(Accessed $2^{\text {nd }}$ December 2016)

[4]. Nelson, S. A. 2015. Physical Geology. Weathering and Soils. EENS 1110. Updated 10 September 2015. Tulane University.http://www.tulane.edu/ sanelson/eens1110/weathering.htm (Accessed 24th November 2016)

[5]. Chernicoff, S. and Venkatakrishnan, R. 1995. Weathering: The breakdown of rocks. In: Geology, Chapter 5, pp. 126 - 149, published by Worth Publishers Inc, New York, New York. ISBN 0-87901 - $451-2$

[6]. Ashman, M. R. and Puri, G. 2003. Essential soil science: a clear and concise introduction to soil science. First published 2002 by Blackwell Science Ltd, reprinted 2003. ISBN 0-632-04885-9.

[7]. Pidwirny, M. 2013. Soil erosion and deposition. Retrieved from http://editors.eol.org/eoearth/wiki/weathering

[8]. Dearman, W. R. 1976. Weathering Classification in the Characterisation of Rock. Bulletin International Association Engineering Geologist, Vol 13.pp.373-381

[9]. Geol. Soc. Eng. Group. Work (UK). 1995. The description and classification of weathered rocks for engineering purpose, Quarterly Journal for Engineering Geology, 28, pp. 207-242.

[10]. Marndi, B. 2011. Stability of Slopes in Iron Ore Mines. B Tech mining engineering thesis, National Institute Technology, India. http://ethesis.nitrkl.ac.in/2608/1/107MN018.pdf (Accessed $2^{\text {nd }}$ December 2016)

[11]. Pradha, S. S. 2014. Stability Analysis of Open Pit Slope using FLAC. Rourkela: National Institute of Technology, India.

[12]. Groundprobe. 2017. Slope stability radar (SSR). http://www.groundprobe.com/news-and-publications/case-studies (accessed 25 April 2017).

[13]. Silwamba, C. and Chileshe, P.R.K. 2016. Radar slope management at Nchanga Open Pit Mine, Zambia: Footwall failure of November 2014. International Journal of Research Science \& Management, May 2016 publication. ISSN: $2349-5197$. www.ijrsm.com

[14]. Edumine. 2016. Average specific gravity for various rock types. http://www.edumine.com/xtoolkit/tables/sgtables.htm (Accessed on 22nd September 2016)

[15]. Fellenius, W. 1936. Calculation of the stability of earth dams. Proc. $2^{\text {nd }}$ Congr. Large Dams, Washington DC.

[16]. Hartman, H. L and Mutmansky, J. M. 2002. Introductory mining engineering. Second edition. Publishers: J Wiley and Sons, Inc., Hoboken, New Jersey, United States of America. ISBN 0- 471-34851-1.

[17]. Kliche, C.A. 2011. Slope stability. Chapter in: SME Mining Engineering Handbook, third edition, Volume 1, edited by Peter Darling, pp.495 - 525. Publisher: Society for Mining, Metallurgy, and Exploration, Inc. ISBN 978-0-87335-264-2. www.smenet.org

[18]. Hoek, E. and Bray, J.W. 1981. Rock Slope Engineering. London: The Institution of Mining and Metallurgy, pp. pp $341-351$. 